\title{
Estratégias e práticas de gestão, orientadas à sustentabilidade organizacional: um estudo em uma cooperativa de crédito no estado do Paraná
}

\author{
Management strategies and practices, oriented on organizational \\ sustainability: a study in a credit cooperative the Paraná state
}

\section{Tatiane Aparecida Penteado', Silvio Roberto Stefano ", Zoraide da Fonseca Costa"I}

\footnotetext{
' Universidade Estadual do Centro-Oeste, Unicentro. tatyane1860@hotmail.com

"Universidade Estadual do Centro-Oeste, Unicentro. professor-silvio@hotmail.com

III Universidade Estadual do Centro-Oeste, Unicentro. zoraide@unicentro.br
}

\section{RESUMO}

O objetivo deste artigo é analisar as relações entre as ações estratégicas de uma cooperativa de crédito rural e as práticas de gestão nas dimensões econômicas, sociais e ambientais da sustentabilidade, por meio do uso dos critérios do Triple Bottom Line (TBL) e de conceitos e práticas relacionados ao cooperativismo de crédito. Quanto à metodologia, esta pesquisa caracteriza-se como estudo de caso único, com natureza aplicada com abordagem qualitativa com técnicas de análise quantitativa. Os resultados evidenciam que a cooperativa analisada do interior do estado do Paraná, não possui equilíbrio nos pilares econômico, social e ambiental para que se tenha vantagem competitiva para com a sustentabilidade organizacional.

Palavras-chave: ações estratégicas, gestão sustentável, cresol. 


\section{ABSTRACT}

This paper is to analyze the relationship between strategic actions of a rural credit cooperative and management practices in the economic, social and environmental dimensions of sustainability, used the Triple Bottom Line (TBL) criteria and concepts and practices related to credit cooperativism. The methodology, this research is characterized as a unique case study, with applied nature with a qualitative approach with quantitative analysis techniques. The results show that the analyzed cooperative from Paraná State, has no balance in the economic, social and environmental pillars so that it has a competitive advantage with organizational sustainability.

Keywords: strategic actions, management practices, cresol.

\section{INTRODUÇÃO}

O desenvolvimento econômico, social e ambiental traz reflexos para a sociedade, criando novas exigências e condicionantes para as atividades das cooperativas. Sendo que a competitividade delas está cada vez mais voltada a uma gestão orientada para a sustentabilidade, que agregue a dimensão econômica, social e ambiental. Nessa perspectiva, esta pesquisa, investiga estratégias e práticas de gestão, orientada à sustentabilidade organizacional, com foco em uma cooperativa de crédito solidário rural como uma proposta de análise do pilar econômico, social e ambiental da sustentabilidade organizacional.

Desta forma, a estratégia como prática e os pilares econômico, social e ambiental da sustentabilidade poderá auxiliar a compreensão dessa pesquisa, que tem como objetivo principal analisar as relações entre as ações estratégicas de uma cooperativa de crédito rural solidário do interior do estado do Paraná e as práticas de gestão nas dimensões econômicas, sociais e ambientais da sustentabilidade. $\mathrm{O}$ problema de pesquisa envolveu: quais as relações entre as ações estratégicas de uma cooperativa de crédito e as práticas de gestão da sustentabilidade?

Para Jarzabkowski, Balogun e Seidl (2007) a estratégia como prática é o conjunto de tarefas concretizadas com base na interação, negociação e ação 
articuladas pelos atores em um dado contexto sócio histórico, e esta sendo cada vez mais utilizada em organizações. A construção e ampliação desse estudo estão estruturados a partir de quatro conceitos fundamentais: repertórios interpretativos, práticas discursivas, práticas organizacionais e práxis. Sendo que a prática está diretamente ligada ao "fazer" da organização, sendo assim, as práticas estão relacionadas as normas, a cultura e todos os procedimentos instituídos ou definidos dentro da organização que direcionam as pessoas na realização de suas atividades organizacionais.

A sustentabilidade deverá estar diretamente integrada às dimensões econômica, social e ambiental, a partir dos estudos de John Elkington, quando cunhou o termo "triple bottom line". Elkington $(2004,2012)$ expõe que buscava em 1994 uma nova linguagem para expressar a ampliação da agenda ambiental que Sustainability (fundada em 1987) estava centrada, dessa forma já existiam outros trabalhos pautados que referiam termos como "excelência ambiental" em 1984 e "consumidor verde" em 1986.

Para Munck (2014) a sustentabilidade organizacional possui foco na criação de valor, no gerenciamento ambiental e capital humano assim como sistema de produção ambientalmente amigável. Deste modo, as ações organizacionais não precisam ser consideradas sustentáveis quando acatarem somente um dos pilares da sustentabilidade.

Do mesmo modo, Porter e Linde (1995) afirmam por meio da Hipótese de Porter (HP) que uma regulamentação ambiental rigorosa quando bem trabalhada tende a gerar uma situação "ganha-ganha", beneficia tanto o meio ambiente quanto a empresa, ressaltam que o problema da legislação não é a rigor (ou sua falta), mas de que maneira as regras são ordenadas e aplicadas. 
Porter e Linde (1995) afirmam que as normas ambientais quando adequadamente planejadas podem estimular inovação compensar os custos do cumprimento com estas normas. Os conceitos a serem adotados para o estudo estão diretamente ligados à problemática da pesquisa, neste sentido os conceitos a serem adotados são ações estratégicas, práticas de gestão, estratégia como prática, dimensões econômicas, sociais e ambientais da sustentabilidade.

A Cresol Vale das Araucárias do interior do estado do Paraná, foi escolhida para a realização da presente pesquisa por acessibilidade e por ser considerada uma instituição financeira cooperativa referência pelo modelo de atuação em sistema (CRESOL, 2018; DIAS, SILVA, LUND, 2019). A seguir apresenta-se o referencial teórico, os procedimentos metodológicos, análises dos resultados e conclusões do estudo.

\section{REFERENCIAL TEÓRICO}

\subsection{Sustentabilidade Organizacional}

O termo sustentabilidade tem sua origem ligada diretamente atrelada ao conceito de desenvolvimento sustentável, estando às primeiras concepções concretizadas na Conferência das Nações Unidas tendo como tema o meio ambiente humano, no ano de 1972 (BRUNACCI E PHILIPPI, 2014).

No entanto, assunto é essencial para que as organizações também tenham conhecimento e compreendam a importância da sustentabilidade, é um assunto que deve ficar não somente ao nível de discussão entre as nações, e sim um problema que deve ser discutido apenas por líderes mundiais, não simplesmente abordar a sustentabilidade, como algo que possa ser custoso ou prejudicial às organizações, mas que as organizações possam adaptar essas práticas em seu cotidiano, no dia a 
dia de suas operações, tornando assim integrante das suas atividades operacionais e de gestão.

Dessa forma, muitas organizações começam a ter novas percepções referente aos melhoramentos que uma empresa sustentável pode apresentar tanto às dimensões econômicas, até mesmo em relação aos seus modos nas questões ambientais e sociais, que fazem com que haja reflexo para a imagem da organização.

Portanto, para que as organizações consigam prosperar em longo prazo, carecem de estratégias voltadas ao desenvolvimento sustentável em suas três dimensões: econômica, social e ambiental, estas devem ser trabalhadas não de forma isolada e sim simultaneamente, para assim poder desenvolver um princípio econômico sustentável, uma vez que uma empresa só será sustentável se trabalhar as três dimensões da sustentabilidade de forma conjunta (ELKINGTON, 2012).

De acordo com Kulak, Stefano e Kuhl (2019), além da compreensão dos beneficio que a sustentabilidade é capaz de causar outro agente que colabora com a aceitação das práticas de sustentabilidade nas organizações é com relação à força praticada por seus parceiros para a aceitação dessas práticas.

Recusar o desafio imposto pelos três pilares é correr o risco de extinção. Esse assunto não diz respeito somente a grandes organizações: estas serão forçadas a repassar a pressão, por meio de cadeia de fornecimento, para seus grandes e pequenos fornecedores e empreiteiros (ELKINGTON, 2012, p. 33).

Percebe-se que embora os desafios para alcançar a sustentabilidade sejam grandes, os benefícios que a sustentabilidade proporciona para as organizações, se 
propagam por toda a sociedade, confirmando-se como um fenômeno de importância coletiva.

Para que se possa atingir o patamar da sustentabilidade e poder usufruir de benefícios, as organizações necessitam procurar o equilíbrio nas três dimensões da sustentabilidade, econômica, social e ambiental, buscando com propósito ser ambientalmente responsável, socialmente justo e economicamente viável, que representa o Triple Bottom Line (TBL), desenvolvido por Elkington (2012).

Elkington (2004, 2012) sobre o conceito de sustentabilidade encontrar-se aprimorado em três pilares, pilar econômico, o pilar social e o pilar ambiental, Sachs (2008, p.15-16) também contribui com o tema apresentando os cinco pilares do DS:

a) Social, é fundamental por motivos tanto intrínsecos quanto instrumentais por causa a perspectiva de disfunção social que paira de forma ameaçadora sobre muitos lugares problemáticos do planeta.

b) Ambiental, com as suas duas dimensões (os sistemas de sustentação da vida como provedores de recursos e como -recipientesll para disposição de resíduos).

c) Territorial, está relacionado à distribuição espacial dos recursos, das populações e das atividades.

d) Econômico, sendo a viabilidade econômica.

e) Político, a governança democrática é um valor fundador e um instrumento necessário para fazer as coisas acontecerem; a liberdade faz toda a diferença (SACHS, 2008, p.15-16). 
De acordo com Kulak, Stefano e Kuhl (2019) os três pilares possuem distintas propriedades e precisam de diferentes abordagens para sua consideração. No entanto as organizações não devem fundamentar suas decisões em apenas um dos pilares, pois pode causar desiquilíbrio em qualquer estratégia organizacional no longo prazo (DYLLICK; HOCKERTS, 2002). Ainda para Dyllick e Hockerts (2002), as organizações necessitam aumentar seus capitais econômicos, sociais e ambientais, de forma equilibrada, para que assim seja atingido a sustentabilidade organizacional.

Para que as organizações consigam atingirem a sustentabilidade, devem alavancar o conceito do TBL proposto por Elkington (2012) sugere a operacionalização de modo integrado das três dimensões, e nesse mesmo fluxo, outros autores como Dyllick e Hockerts (2002) e Jamali (2006), demonstram argumentos que admitem a transformar os pilares da sustentabilidade organizacional (SO) em três sustentabilidades: organizacional econômica, organizacional social e organizacional ambiental. Estas se tornam sustentadora e viabilizadoras da SO, sendo assim, para uma organização consegui buscar o estado de sustentabilidade, deve primeiro desenvolver suas sustentabilidades econômica, social e ambiental de forma equilibrada.

As organizações começaram a aderir a regulamentos unificados e adotados, com o intuito de empregar e fortalecer suas atuações e posição no mercado, isso aconteceu devido às pressões ambientais ocorreu o aumento da legitimação da sustentabilidade e a oportunidade de contestação social, Pode-se explicar essa aderência como institucionalização de práticas sustentáveis (WOLFFENBÜTTEL, 2015).

A tendência é que cada vez mais as organizações coloquem em suas rotinas as práticas sustentáveis em suas atividades com intuito de fazer com que sejam reconhecidas em suas organizações, tornando-as, assim, institucionalizadas em suas funções operacionais, sendo por iniciativas consequentes de pressões desenvolvidas pela sociedade e parceiros da organização ou por iniciativas próprias, assim como 
será debatido no tópico seguinte o qual discorre sobre estratégia como prática voltada para os pilares sociais e ambientais da sustentabilidade.

\subsection{Estratégia como Prática}

A estratégia como prática faz parte de um movimento muito amplo voltado a estratégia organizacional que tem ganhado cada vez mais espaço na ciência social contemporânea, encontra-se no cotidiano de relatos dos atores sociais com relação em processos estratégicos em uma probabilidade longitudinal de diagnóstico e teve de ligar em seu corpo analítico teorias de proximidade ontológica e epistemológica, tais como o Estruturacionismo (Giddens, 2003 e 1984) e a Teoria da Visão Baseada na Atividade (Jarzabkowski, 2005), para que suportem suas finalidades e que possuam influência mútua de crítica para a ampliação coerente de suas estratégias e métodos de pesquisa no campo em expansão. Iniciada por autores como Pierre Bourdieu, Michael de Certeau, Michel Foucault e Anthony Giddens, que compartilham a ideia do ator como um agente de ação, responsável pela construção da realidade, que ocorre por meio da dialética entre agente e ambiente (BERGER; LUCKMANN, 2004).

As práticas consistiriam em produto e produtora das relações sociais articuladas entre os influentes coletivos que atuam em uma organização. Sendo que, estas atividades humanas são atingidas como algo socialmente organizadas, sendo formadas por diversas ações que se localizam no tempo e espaço históricos (SROUR, 2012). Estas relações organizadas são distinguidas por:

A) Relações de haver (produção) que definem uma espécie de "praça" em bens materiais e serviços são produzidos e trocados no mercado; B) Relações de poder que delimitam arenas políticas em diferentes agentes coletivos travam lutas para fazerem prevalecer os seus interesses; C) Relações de saber que gera uma espécie de 
palco em que são construídos e difundidos sentidos e outros elementos simbólicos (SOUR, 2012 p.82).

Para Srour (2012) estas relações coletivas proferem agentes coletivos que possuam interesse em levantar realidades material e imaterial, objetividade e subjetividade, abalizando métodos de modificação da natureza, das organizações e transformando em atividades padronizadas que formam as práticas sociais e organizacionais que movimentam agentes, recursos material e imaterial.

Contextualizando o surgimento e a expansão da estratégia como prática a partir da demanda reprimida surge à precisão de que sejam observados os estudos em Estratégia "por outra perspectiva", quando é notado certo declínio na contribuição de conceitos mais antigos e técnicas de análise, sendo que este não é explicado com profundidade à forma real dos métodos e implicações sociais dos intérpretes envolvidos na estratégia operacionalizada no dia a dia das organizações (WHITTINGTON, 2006).

Assim, na proposta de Whittington (2006), a prática da estratégia está relacionada a três elementos, que podem ser considerados isoladamente, a saber: a prática, a práxis e os participantes. A prática expõe a respeito às formas de decisão estratégica, ferramentas, normas, discursos e procedimentos que dão direção às atividades cotidianas; a práxis são as atividades ligadas no "fazer estratégia", consiste na forma de trabalho da estratégia e como ela se concretiza na organização. É a atividade que é realizada pelo participante; e participante é aquele que executa as práticas, a pessoa que tem envolvimento com o "fazer estratégia".

O autor idealiza a práxis como o trabalho transformam e replicam as práticas da estratégia de que forma que os praticantes estratégicos atingem (WHITTINGTON, 2006). No entanto, abordar a estratégia como práxis constitui em compreender a integração reflexiva entre teoria e prática. De modo que cabe dar destaque à esta 
integração não implica que a percepção de práxis seja equivalente a de prática. A partir destes elementos, Jarzabkowski et al. (2007) propuseram um quadro conceitual para se analisar a estratégia como prática, conforme apresentado na figura 1.

Figura 1: Escopo conceptual para analisar a estratégia como prática

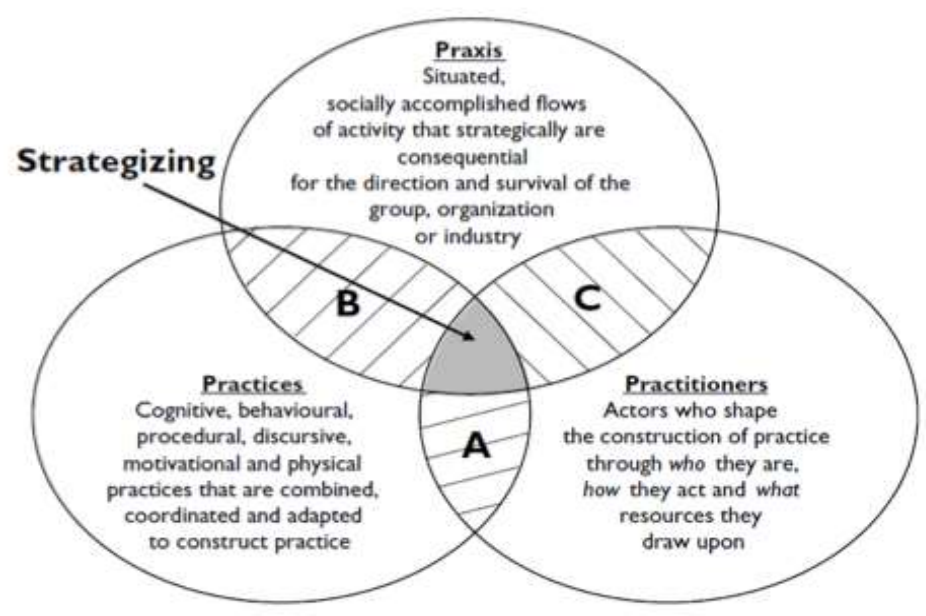

Fonte: Jarzabkowski, Balogun e Seidl (2007, p.7).

Por meio da figura 1, Jarzabkowski et al. (2007) buscaram explicar a conjunção da prática, práxis e participantes, dá origem ao Strategenzing, o "fazer estratégia". Okayama et al. (2014) esclarecem que os pontos A, B e C, da figura, concebem maior foco em um verificado quesito, conforme o objetivo da pesquisa a ser dirigida. Porém, conforme Johnson et al. (2007), os elementos, assim como seus pontos de interseção, não são estáticos, mas alteram-se conforme a influência das atividades na estrutura (OKAYAMA et al., 2014).

Desta forma, esta pesquisa tem como foco os participantes. Analisando que os participantes de estratégia, segundo Jarzabkowski e Whittington (2008) são os consultores, os analistas, reguladores, os gestores de projetos, os gestores de topo e os gestores intermediários, as pessoas que influenciam a estratégia de uma organização, assim como uma das sugestões de pesquisa da estratégia como prática proposta por Vara e Whittington (2012), onde sugerem verificar como ocorre a 
participação, a inclusão, a (des) igualdade de gênero e a capacitação dos indivíduos na estratégia, o foco de estudo são as mulheres em cargos de liderança, entendendo estas como participantes do "fazer estratégia".

\subsection{Cooperativismo e Cooperativismo de Crédito}

Acredita-se que as organizações cooperativadas possuem seus princípios, missão visão e valores e uma história de maior relação com os preceitos da sustentabilidade do que as demais empresas, devido aos seus diferenciais sociais históricos, como pode ser evidenciado nos princípios do cooperativismo no interesse pela comunidade, onde as cooperativas devem trabalham para o desenvolvimento sustentado das suas comunidades por meio de políticas aprovadas pelos membros como apontado por Scheidt; Stefano; Kos (2019). Outro aspecto relevante é o interesse pela comunidade que exige das cooperativas o apoio a projetos e soluções que sejam sustentáveis tanto do ponto de vista econômico (para a perpetuidade do próprio empreendimento), como sob a ótica social e ambiental (PCF, 2020).

De acordo com Frank (1973) a palavra cooperativismo pode ter duas acepções. Por um lado caracteriza o sistema de organização econômica, que busca acabar com os desajustes sociais resultante dos exageros da intercessão capitalista; por outro, indica a doutrina corporificada no contíguo de fundamentos que devem controlar o comportamento do homem incorporado naquele sistema.

Ainda para Frank (1973), sob ponto de vista econômico, a cooperativa não tem como intuito explorar serviços nos seus próprios interesses, mas para prestá-los desinteressadamente aos cooperados. Desse modo pressupõe um ideário socioeconômico, que pode também ser chamado, de Solidarismo. A solidariedade, quando bem aplicada à área cooperativa, incide em garantir a todos os cooperados, vantagens do empreendimento comum. 
Conforme a Constituição Federal, as Cooperativas de Crédito são consideradas:

ART. 146 - Cabe à lei complementar: III - estabelecer normas gerais em matéria de legislação tributária, especialmente sobre: c) adequado tratamento tributário ao ato cooperativo praticado pelas sociedades cooperativas;

Art. 192 - Do Sistema Financeiro Nacional - O sistema financeiro nacional, estruturado de forma a promover o desenvolvimento equilibrado do País e a servir aos interesses da coletividade, em todas as partes que o compõem, abrangendo as cooperativas de crédito, será regulado por leis complementares que disporão, inclusive, sobre a participação do capital estrangeiro nas instituições que o integram (BRASIL, 1988).

Segundo Irion (1997, p.35) “cooperativismo é instrumento eficaz para a organização da população, a democracia dos investimentos, a distribuição da renda, a regularização do mercado, a geração de empregos e assim instrumentaliza a justiça social". Meinen e Port (2012) que a grande diferença em relação às outras iniciativas de caráter empresarial, nota-se uma preocupação com valores e ideais humanitários nas definições, independentemente da fonte. Desde o surgimento na primeira metade do século XIX, em Rochadale, na Inglaterra, o cooperativismo é o único movimento socioeconômico que cresce sob uma mesma orientação doutrinária. (MEINEN; PORT, 2012). As cooperativas assim como nos negócios são direcionadas por valores, não apenas por lucros, partilham internacionalmente princípios e atuam em conjunto para estabelecer um mundo melhor pelo meio de cooperação $(\mathrm{ACl}$, 2020).

Ao tratar da doutrina cooperativista, Cruz (2001, p. 49) destaca três aspectos: 
[...] valores - são experiências morais, de caráter permanente, que se constituem no arcabouço do pensamento e da conduta dos cooperativistas; princípios são as regras de conduta que devem ser observadas, em decorrência da aplicação dos valores nas situações mais específicas do relacionamento social do cooperativismo e dos cooperados em geral, cuja evolução e aperfeiçoamento constantes, devem fazer parte das transformações preconizadas pelo cooperativismo; herança histórica - é todo o acervo intelectual, legado pelos socialistas precursores do cooperativismo, representado por todos os seus pensadores e ideólogos e, também, pela evolução das ideias por eles defendidas, ao longo de todo o processo histórico, que consolidou a filosofia cooperativista em todo o mundo.

Os valores e os princípios, juntos com as ideias gerais formam a base doutrinária do cooperativismo. Esses se caracterizam por seu caráter abrangente e perene no tempo. Os princípios interpretam o tempo os valores e se adaptam ao tempo e lugar. Sendo assim, os valores tomam posição superior na hierarquia da doutrina cooperativista. Pode-se dizer que os princípios explicam os valores e fazem a ligação entre a teoria e a prática cooperativista. Os princípios convertem ideias em ação. Segundo ACl (2020), as cooperativas se baseiam nos valores de autoajuda, auto irresponsabilidade, democracia, igualdade, equidade, e solidariedade.

Para Scheidt; Stefano; Kos (2019) o objetivo das cooperativas, diferente das empresas, não é lucrar, mas melhorar as condições de vida de seus membros. As cooperativas são formas de organização, pautadas pelos valores da democracia, da igualdade, da ajuda mútua, da solidariedade, da autonomia, da equidade e da responsabilidade, que envolvem atividades socioeconômicas e que têm como missão atender às necessidades de seus associados. Destaca-se o princípio da 
responsabilidade socioambiental, que é o compromisso com o bem-estar das pessoas, proteção do meio ambiente, preocupação com o desenvolvimento econômico e social.

Os valores do cooperativismo têm uma ampla adesão aos conceitos da sustentabilidade. Meinen e Port (2012) citam que devido ao seu significado e atualidade a palavra sustentabilidade é a chave e será provavelmente um novo princípio de cooperativismo. A seguir apresentam-se os procedimentos metodológicos da pesquisa.

\section{PROCEDIMENTO METODOLÓGICO}

Quanto à metodologia, esta pesquisa caracteriza-se como estudo de caso único, com natureza aplicada com abordagem qualitativa. A abordagem qualitativa centra-se na identificação das distinções de situações, eventos e organizações (LLEWELLYN; NORTHCOTT, 2007).

Os construtos desta pesquisa são: estratégicas e práticas de gestão que tem por finalidade verificar dentro do pilar econômico, social e ambiental da sustentabilidade organizacional. O questionário e o roteiro de entrevistas foi baseado no TBL de Elkington $(2004,2012)$ com o pilar econômico, o pilar social e o pilar ambiental. Já as relações sobre a estratégica como prática foram adaptadas da pesquisa de Lima (2013), considerando a proposta teórica de Whittington (2006), onde a prática da estratégia está relacionada a três elementos, que podem ser considerados isoladamente.

As etapas foram análise entrevistas com os gestores na cooperativa e aplicação de questionários aos colaboradores da cooperativa. Foi realizado entrevistas semiestruturadas com gestores da cooperativa e, posteriormente foram transcritas e analisadas segundo inspiração da análise de conteúdo temática. Cabe ressaltar que a entrevista, em seu sentido amplo, é uma estratégia empregada no 
processo de trabalho de campo composta de uma conversa a dois, ou entre vários interlocutores, realizada pela iniciativa do entrevistador tem como objetivo adquirir informações relacionadas a um objeto de pesquisa (MINAYO et al., 2007).

O perfil dos entrevistados compreende dentre outras questões: sexo; idade (anos completos); relação de emprego (efetivo/comissão); tempo de trabalho na organização (anos); classe profissional; formação acadêmica e cargo, conforme o Quadro 1 a seguir:

Quadro 1: Perfil dos entrevistados

\begin{tabular}{|c|c|c|c|c|c|c|}
\hline Nome & Sexo & Idade & $\begin{array}{c}\text { Relação de } \\
\text { emprego }\end{array}$ & $\begin{array}{c}\text { Tempo na } \\
\text { organização }\end{array}$ & $\begin{array}{c}\text { Formação } \\
\text { acadêmica }\end{array}$ & Cargo \\
\hline A & Masculino & 37 & Efetivo & 17 anos & Contábeis & Gerente comercial \\
\hline B & Masculino & 32 & Efetivo & 10 anos & $\begin{array}{c}\text { Administraçã } \\
0\end{array}$ & $\begin{array}{c}\text { Gerente Administrativo } \\
\text { Financeiro }\end{array}$ \\
\hline
\end{tabular}

Fonte: A pesquisa.

Para a análise quantitativa foi aplicado questionários survey aos colaboradores. "Um questionário pode ser não estruturado, semiestruturado ou altamente estruturado, [...] um questionário deve produzir dados precisos e confiáveis passíveis de análise estatísticas com pacotes de software como SPSS." (HAIR JR et al., 2005, p.168). Nesse sentido, o survey se aplica a esse estudo, pois seu foco de interesse é apropriado para entender questões do tipo "o que" está ocorrendo, "como", "por que" e "quando", identificando assim quais são as práticas de sustentabilidade existentes na cooperativa de crédito (ALYRIO, 2009). 
Tabela 1 Caracterização do perfil dos respondentes

\begin{tabular}{|c|c|c|c|}
\hline Variável & Tipo & Frequência & Porcentua \\
\hline \multirow{2}{*}{ Sexo } & Feminino & 15 & $65,22 \%$ \\
\hline & Masculino & 8 & $34,78 \%$ \\
\hline \multirow{6}{*}{ Faixa Etária } & 18 a 24 anos & 3 & $13,05 \%$ \\
\hline & 25 a 29 anos & 12 & $52,17 \%$ \\
\hline & 30 a 39 anos & 7 & $30,43 \%$ \\
\hline & 40 a 49 anos & 0 & $0 \%$ \\
\hline & 50 a 59 anos & 1 & $4,35 \%$ \\
\hline & Acima de 60 anos & 0 & $0 \%$ \\
\hline \multirow{3}{*}{ Estado Civil } & Solteiro (a) & 9 & $39,13 \%$ \\
\hline & Casado (a) & 13 & $56,52 \%$ \\
\hline & Outro & 1 & $4,35 \%$ \\
\hline
\end{tabular}

Fonte: A pesquisa.

As respostas para os questionários survey foram coletadas por meio de uma escala Likert (Likert, 1932) de cinco pontos conforme segue:

(1) Discordo totalmente,

(2) Discordo parcialmente,

(3) Indiferente,

(4) Concordo parcialmente,

(5) Concordo Totalmente

Em referência a escala Likert Ghiglione e Matalon (1995, p.292) comentam que os preconizados desta propôs um método de calculo de resultados final através de 
um média ponderada das respostas dadas, atribuindo para cada item um peso $(1,2,3,4,5)$ por nível de concordância expresso pelo sujeito.

Esses pesos ( $\rho$ ) são calculados e demonstrados na apresentação e analise de resultados dos quesitos do questionário por meio da média das ponderações $(\gamma)$ por questão (q) considerando colaboradores respondentes ( $n$ )

$$
\gamma_{q i}=\frac{\sum_{i=1}^{n} p_{q i}}{n}
$$

Quanto às questões socioeconômicas será aplicado a Taxa de Frequência (TF) as categorias de: Gênero, Estado Civil, Renda Familiar, Faixa Etária, Grau de Instrução e Procedência (Cidade).

$$
T F=\frac{f_{i}}{n} \times 100
$$

A TF (Taxa de frequência) é dada pela razão entre a frequência dicotômica (fi) e o número total de respondentes ( $n$ ).

No caso das questões de controle, as quais têm a finalidade de aferir as práticas de sustentabilidade organizacional citadas pelos colaboradores em comparação com as práticas citadas pelos gestores, serão analisadas por meio de um framework.

Já para o cunho qualitativo foram aplicadas entrevistas com 7 questões, a partir da transcrição das entrevistas, da técnica de observação, do diário de campo e do referencial teórico se realizará as análises, tendo como base a análise de conteúdo. Segundo Bardin (2011), esta análise auxilia o pesquisador a analisar os 
dados com objetividade e clareza. Para a autora, a análise de conteúdo é baseada na inferência de conhecimentos e análise de comunicações referentes aos dados coletados (BARDIN, 2011). Para as análises qualitativas das entrevistas será aplicada a análise do conteúdo por avaliação.

Nessa perspectiva, em posse dos dados, estes foram organizados em uma tabela (Framework), relacionando as fontes e os instrumentos utilizados na coleta de dados (pré-análise). Depois, os dados agruparam-se em categorias, classificando os fragmentos das entrevistas que foram transcritos e dos dados coletados nos questionários.

Também, foi utilizada a triangulação dos dados, sendo sua escolha justificada por permitir abordagens metodológicas distintas para verificar o mesmo fenômeno estudado (CRESSWELL; CLARK, 2013). Ou seja, os dados foram triangulados, inicialmente, para um mesmo processo a partir de diferentes fontes, depois entre os processos e, finalmente, entre os resultados e a teoria.

Por fim, os resultados foram mostrados por meio de framework, abrangendo as políticas, estratégias e ações, considerando as dimensões e as condições de presença e ausência das mesmas, aferidas por meio da comparação entre as respostas dos gestores e dos colaboradores, conforme layout. A seguir apresenta-se os resultados, análises e discussões.

\section{ANÁLISE DE RESULTADOS}

No Brasil em 2018, eram 929 cooperativas de crédito em funcionamento com mais de 8 milhões e 900 mil associados e mais de 60 mil funcionários (DIAS, SILVA, LUND, 2019), cada uma com estratégia e planejamento estratégico próprio.

O Sistema Cresol Confederação é composto pela Central Cresol Baser, Central Cresol Sicooper, Ascoob e Cresol Central. A Confederação de Cresol em 2018 contava 
com mais de 500 mil associados, com 528 agências de relacionamento, patrimônio líquido de $R \$ 1,01$ bilhão, $R \$ 2,76$ bilhões em depósitos; $R \$ 2$ bilhões em créditos comerciais; $R \$ 3,14$ bilhões em créditos rurais; $R \$ 7,84$ bilhões no total de ativos. Em relação ao crédito rural, os valores em 2018 , foram de mais de $R \$ 1,3$ bilhão em empréstimos, o que corresponde a 35 mil contratos, dos quais $\mathrm{R} \$ 770$ milhões em financiamentos e R $\$ 520$ milhões em investimentos (DIAS, SILVA, LUND, 2019).

A Cooperativa pesquisada do interior do estado do Paraná foi a Cooperativa de Crédito Rural com Interação Solidária - CRESOL Vale das Araucárias, com sede Regional no município de Guarapuava, a qual possui área de atuação em 11 agência de relacionamento, sendo duas agências localizada em Guarapuava e as demais em Bituruna, Ligação, Palmital, Guamiranga, Pinhão, Turvo, Prudentópolis, Reserva do Iguaçu, Santa Maria do Oeste (CRESOL, 2018).

No que se refere à teoria base do estudo, existe a relação positiva entre a estratégia como prática e os elementos das dimensões da sustentabilidade organizacional, a qual revela que os achados desta pesquisa podem ampliar o foco conceitual e as práticas na cooperativa em estudo, principalmente na dimensão social e ambiental, o qual tem pouca intensidade, conforme verificado através da análise da estatística descritiva, onde o construto dimensão ambiental teve menor frequência nas respostas.

Ao confrontar as respostas dos gestores com a dos colaboradores, através das duas questões-controle aplicadas nos questionários, na primeira questão que buscava identificar se os colaboradores tinham conhecimento de alguma(s) prática(s) de gestão orientada para a sustentabilidade organizacional nas dimensões econômica, social e ambiental que tenha $(m)$ contribuído para a melhoria das práticas de gestão e/ou para a conscientização dos cooperados da cooperativa, foi possível notar que os colaboradores têm conhecimento das práticas de gestão orientadas para a sustentabilidade, e até citaram alguns programas desenvolvidos em escolas e 
também com jovens; foi citado que em algumas cidades há grupos que recebem orientação técnica para melhorias das propriedades, para o descarte correto do lixo, incentivo ao plantio de outras culturas, onde não se tenha que utilizar muito agrotóxico e gere mais renda para a família, e entre todos esses, o mais citado foi o programa "Olhar para o Futuro", "Programa para o Jovens" e o "Programa Juventude Cooperativista".

Quanto à segunda questão, por meio da qual foi questionado se o colaborar teria alguma sugestão de prática de gestão orientada para a sustentabilidade organizacional nas dimensões econômica, social e ambiental que poderia ser implementada pela cooperativa para a melhoria das estratégias de gestão, responderam que seria muito interessante um programa que ensinasse sobre educação financeira para as crianças; inserção de plano econômico, englobando os cooperados, voltado à sustentabilidade organizacional; divulgação de material que apoie a sustentabilidade, principalmente nas escolas rurais, onde a Cresol possui sua maior abrangência de cooperados; desenvolver projetos voltados ao incentivo da produção de orgânicos; implantar a ideia de que se desenvolva artesanatos locais, onde se busque implantar estes produtos no mercado, por meio de pequenas cooperativas que façam este comércio; a geração de renda, onde jovens agricultores tenham mais incentivos à permanência junto as suas famílias. Através das respostas é possível afirmar que a cooperativa pode desenvolver novas estratégias e práticas voltadas para a sustentabilidade, não só econômica, mas também social e ambiental.

Quadro 2: Estatística descritiva das questões de práticas de gestão de sustentabilidade organizacional

\begin{tabular}{|l|l|l|l|l|l|l|l|l|l|}
\hline Questões & $\begin{array}{c}\text { Frequência } \\
\text { (Percentual) }\end{array}$ & 1 & 2 & 3 & 4 & 5 & Média & $\begin{array}{c}\text { Desvio } \\
\text { Padrão }\end{array}$ & $\begin{array}{c}\text { Coeficiente de } \\
\text { variação }\end{array}$ \\
\hline
\end{tabular}




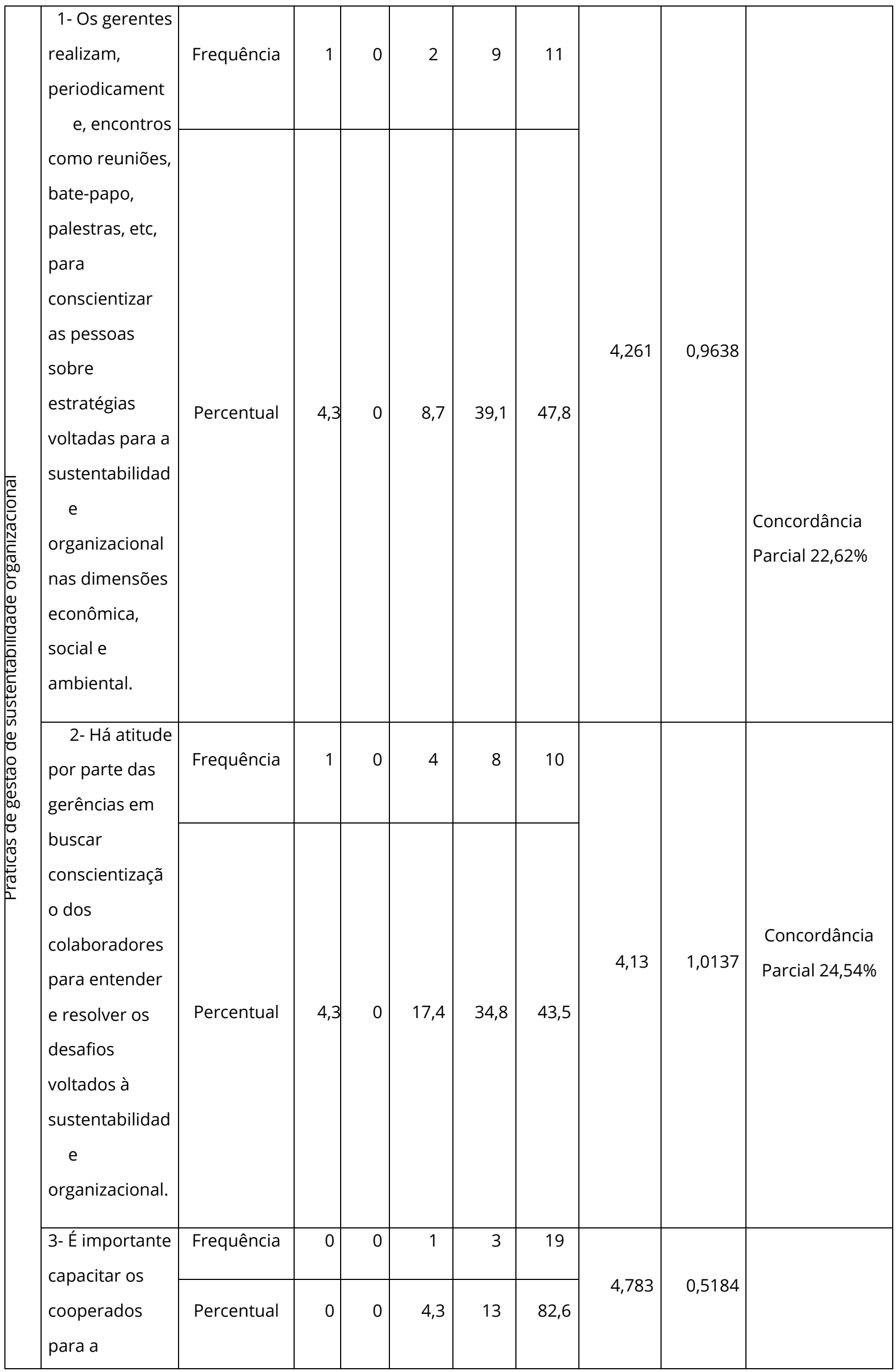

RGC, Santa Maria, v. 8, n.15, Jan./Jun., 2021. 


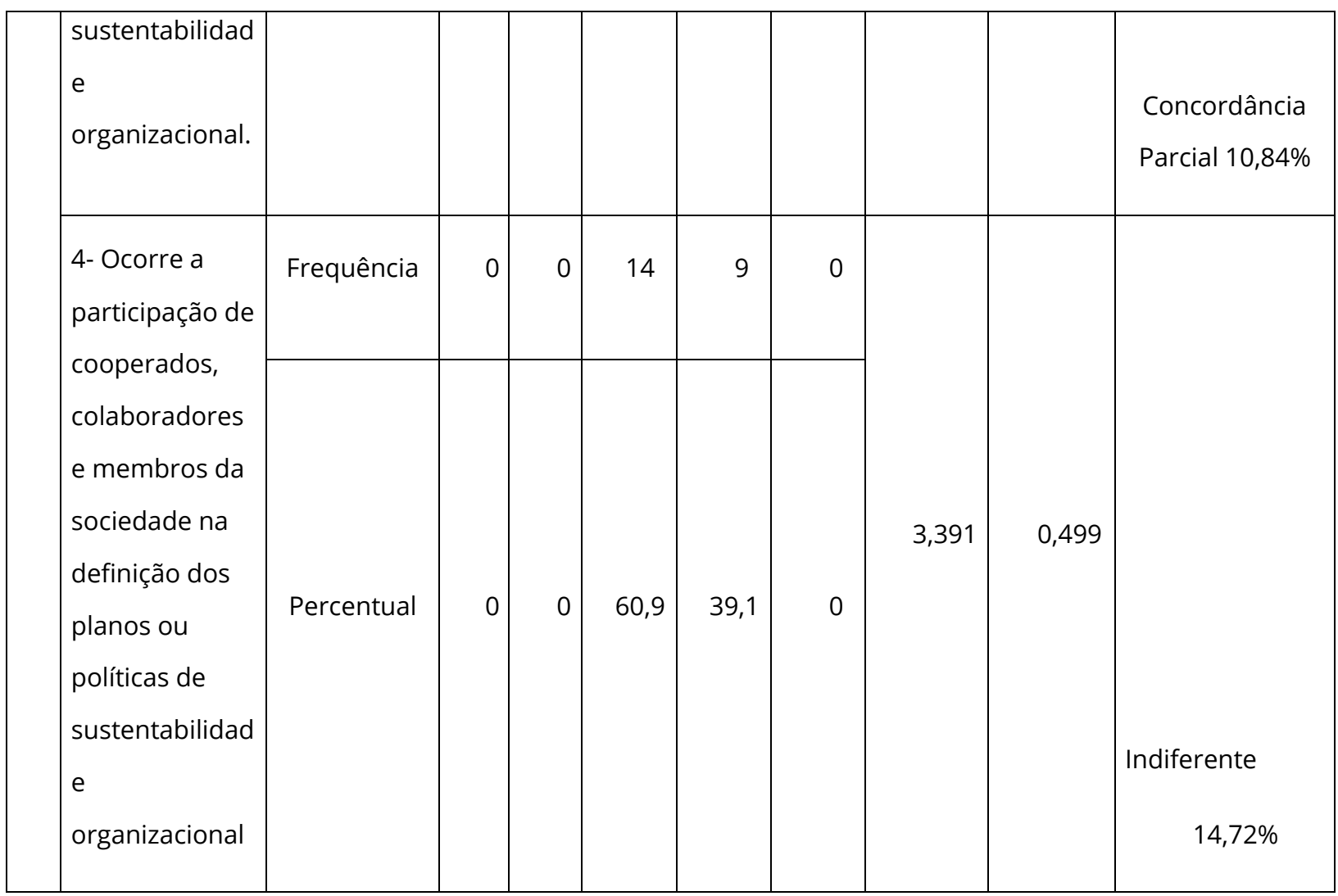

Fonte: A pesquisa e output SPSS.

Observa-se, de um modo geral, que as médias no quadro 2 revelam concordância parcial ou indiferença, indicando que a maioria dos respondentes pensam de forma similar. Outro elemento demonstrado no quadro 2 refere-se ao verificado no desvio padrão da iniciativa, na questão: Há atitude por parte das gerências em buscar conscientização dos colaboradores para entender e resolver os desafios relacionados às questões de transferência de conhecimento voltadas à sustentabilidade organizacional.

Quadro 3: Estatística descritiva das questões de dimensão econômica

\begin{tabular}{|c|r|r|r|r|r|r|r|r|r|r|}
\hline & Questões & $\begin{array}{c}\text { Frequência } \\
\text { (Percentual) }\end{array}$ & 1 & 2 & 3 & 4 & 5 & Média & $\begin{array}{c}\text { Desvio } \\
\text { Padrão }\end{array}$ & $\begin{array}{c}\text { Coeficiente de } \\
\text { variação }\end{array}$ \\
\hline 岕 & 5- A & Frequência & 1 & 0 & 4 & 9 & 9 & 4,087 & 0,996 & \\
\hline
\end{tabular}




\begin{tabular}{|c|c|c|c|c|c|c|c|c|c|}
\hline $\begin{array}{c}\text { Cooperativa } \\
\text { explora e } \\
\text { busca } \\
\text { melhores } \\
\text { práticas } \\
\text { para } \\
\text { desenvolver } \\
\text { suas } \\
\text { atividades } \\
\text { econômicas } \\
\text { e de seus } \\
\text { cooperados. }\end{array}$ & Percentual & 4,3 & 0 & 17,4 & 39,1 & 39,1 & & & $\begin{array}{l}\text { Concordância } \\
\text { Parcial 24,37\% }\end{array}$ \\
\hline $\begin{array}{c}\text { 6- A } \\
\text { Cooperativa } \\
\text { busca o } \\
\text { crescimento } \\
\text { do volume } \\
\text { de crédito } \\
\text { concedido e } \\
\text { adesão de } \\
\text { novos } \\
\text { cooperados. }\end{array}$ & Frequência & 0 & 0 & 8,7 & 21,7 & 16 & 4,609 & 0,6564 & $\begin{array}{l}\text { Concordância } \\
\text { Parcial 14,24\% }\end{array}$ \\
\hline $\begin{array}{c}\text { 7-A } \\
\text { empresa } \\
\text { busca } \\
\text { ampliar a } \\
\text { sua } \\
\text { participação } \\
\text { no mercado. } \\
\text { (novos } \\
\text { cooperados) }\end{array}$ & Frequência & 0 & 0 & 8,7 & 17,4 & 73,9 & 4,652 & 0,6473 & $\begin{array}{l}\text { Concordância } \\
\text { Parcial 13,91\% }\end{array}$ \\
\hline 8- A & Frequência & 0 & 1 & 5 & 6 & 11 & 4,174 & 0,9367 & \\
\hline
\end{tabular}




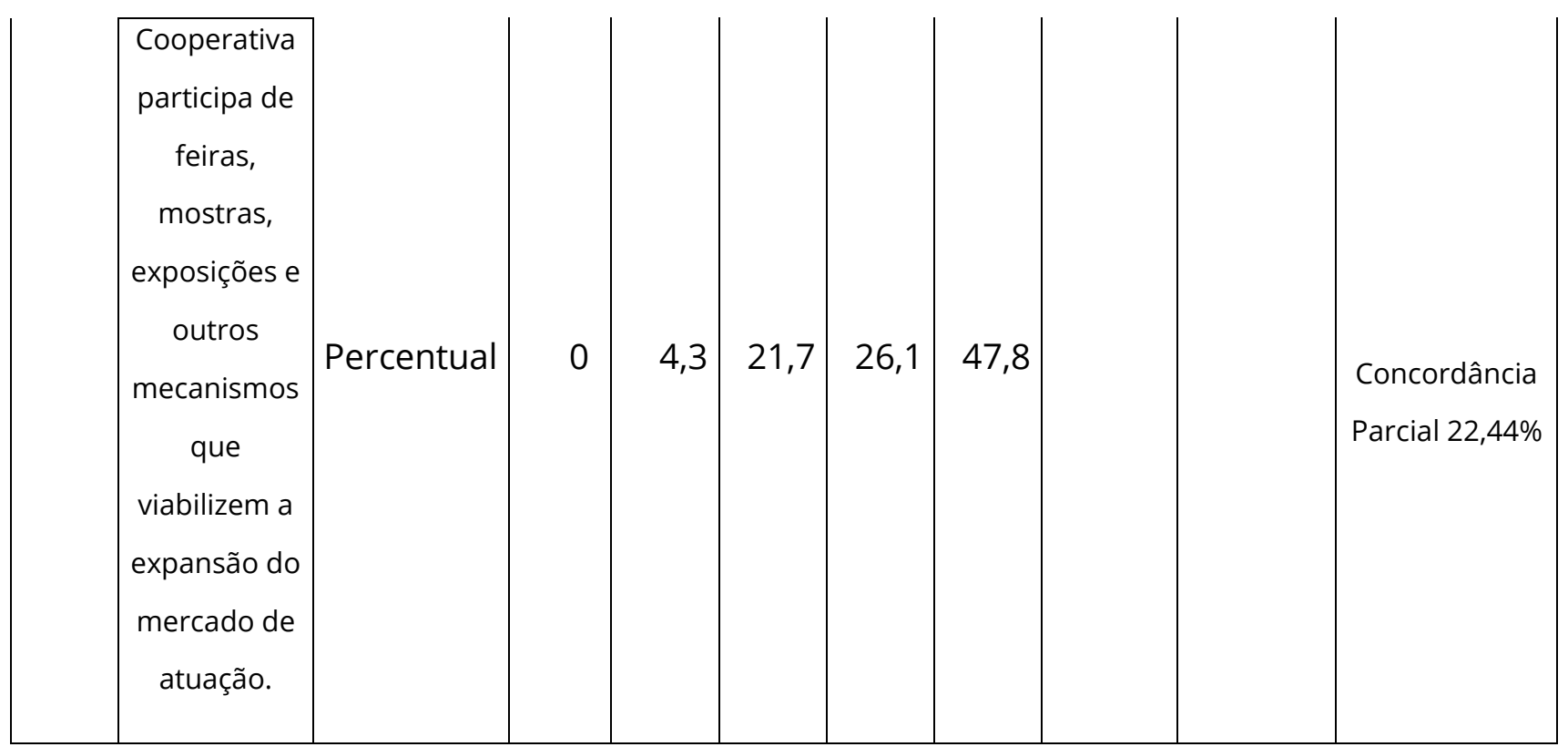

Fonte: A pesquisa e output SPSS.

É possível observar que houve concordância parcial com respostas homogêneas, ou seja, os colaboradores pensam de forma similar quanto às questões 5, 6, 7 e 8. No quadro 3, no constructo dimensão econômica, que a questão que obteve maior frequência foi "A Cooperativa busca o crescimento do volume de crédito concedido e adesão de novos cooperados", visto que a cooperativa em estudo tem como foco principal o crescimento econômico. A menor frequência foi 9 (nove) para a questão: A Cooperativa explora e busca melhores práticas para desenvolver suas atividades econômicas e de seus cooperados. A Nota dada a essa questão demonstra que a cooperativa pode explorar mais as práticas para desenvolver atividades econômicas de seus cooperados. Observa-se as médias no quadro 3, em que a mesma ficou entre 4 ou muito próximo de 5 , indicando que a maioria dos respondentes responderam afirmando que a cooperativa se enquadra no pilar econômico. 
Quadro 4: Estatística descritiva da dimensão ambiental

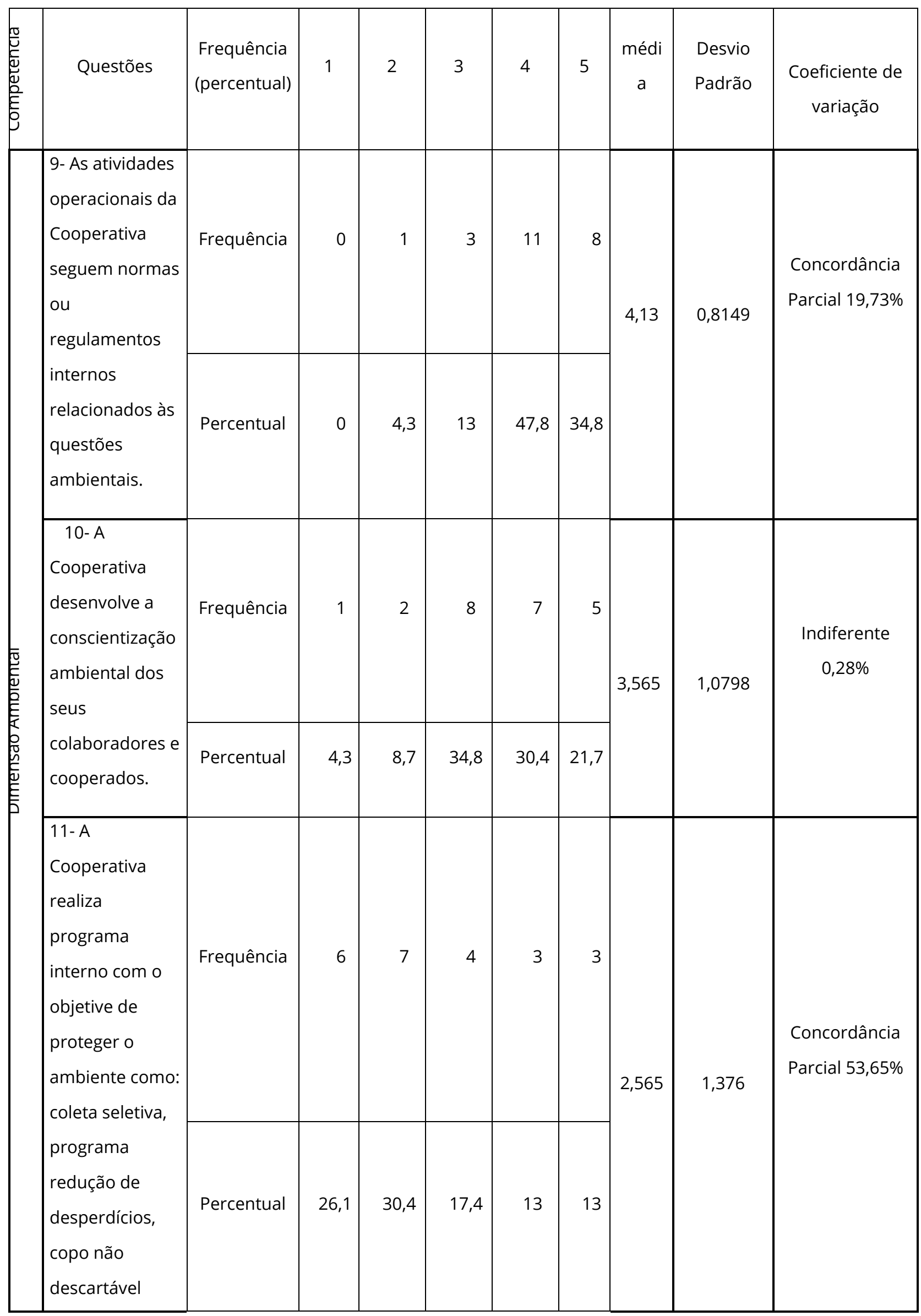




\begin{tabular}{|c|c|c|c|c|c|c|c|c|c|}
\hline $\begin{array}{l}\text { para } \\
\text { colaborador ou } \\
\text { outros. }\end{array}$ & & & & & & & & & \\
\hline $\begin{array}{l}12-\mathrm{A} \\
\text { Cooperativa } \\
\text { trabalha com } \\
\text { programas, } \\
\text { metas ou } \\
\text { obietivos }\end{array}$ & Frequência & 4 & 6 & 8 & 4 & 1 & \multirow[t]{2}{*}{2,652} & \multirow[t]{2}{*}{1,1123} & \multirow[t]{2}{*}{$\begin{array}{l}\text { Concordância } \\
\text { Parcial 41,94\% }\end{array}$} \\
\hline $\begin{array}{l}\text { organizacionais } \\
\text { com vistas a } \\
\text { obter } \\
\text { certificação } \\
\text { ambiental. }\end{array}$ & Percentual & 17,4 & 26,1 & 34,8 & 17,4 & 4,3 & & & \\
\hline
\end{tabular}

Fonte: A pesquisa e output SPSS.

Nessas questões é possível verificar a frequência de respondentes que discordam totalmente de algumas práticas ambientais e programas internos que objetivem a proteção do meio ambiente, sendo assim justificadas devido as boas práticas de sustentabilidade na cooperativa estarem vinculadas diretamente à gestão de riscos socioambientais, a qual encontra-se atrelada de forma indireta às ações da cooperativa. Porém, tais práticas, por vez podem não ser manifestadas nas atuações diárias da cooperativa de forma idêntica ao conceito teórico usado no referencial do trabalho, e desta forma não serem percebidas nos serviços financeiros oferecidos aos cooperados da cooperativa.

Com relação às médias, pode-se observar no quadro 4 que a mesma ficou entre 2 (dois) e 4 (quatro), indicando que a maioria dos colaborados responderam de forma negativa às questões. Outro elemento demonstrado no quadro 4 refere-se ao verificado no desvio padrão, onde é muito próximo, sem muita dispersão, o que permite afirmar não haver dispersão. 
Quadro 5: Estatística descritiva das questões de dimensão social

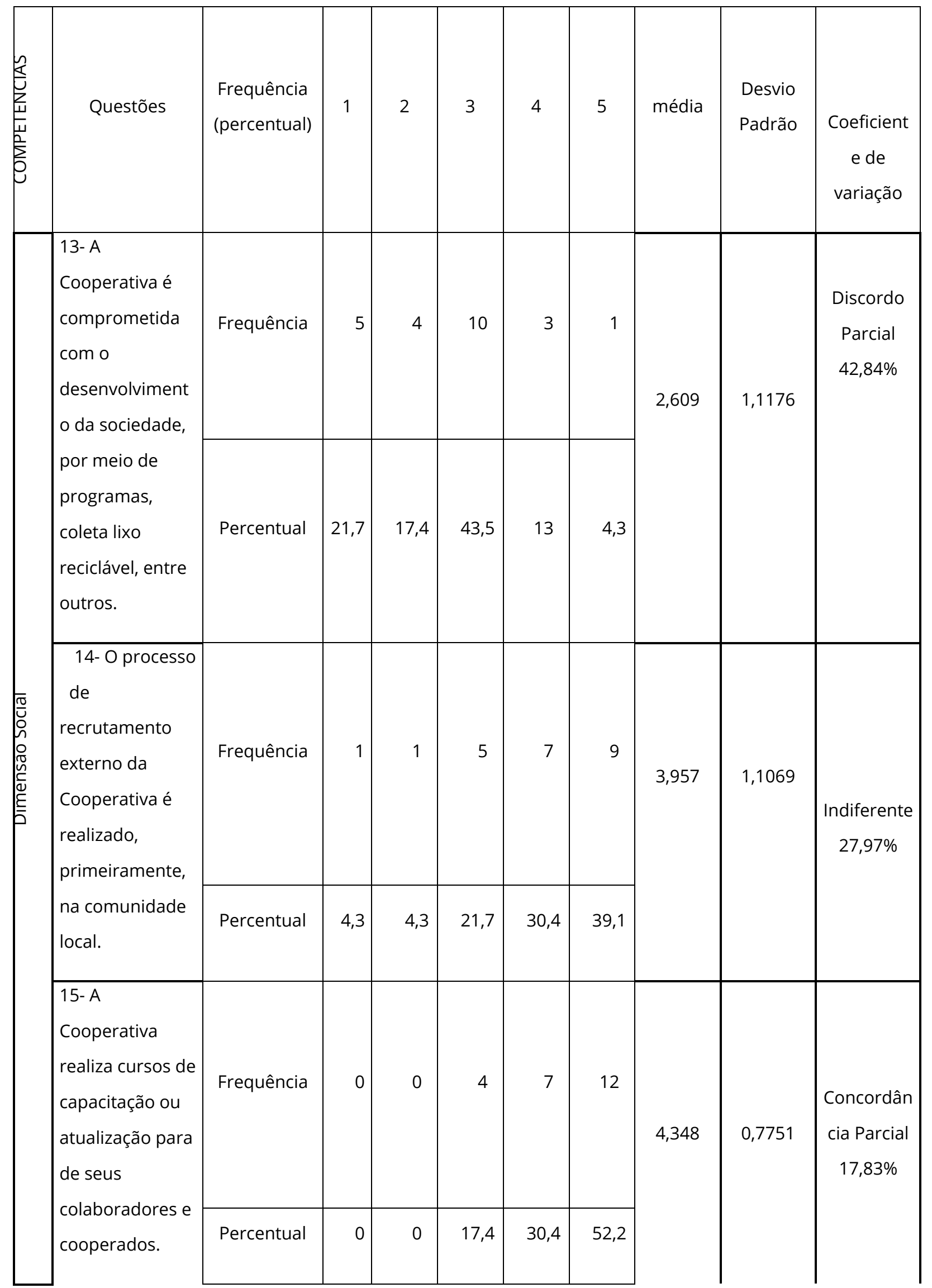




\begin{tabular}{|c|c|c|c|c|c|c|c|c|c|}
\hline $\begin{array}{l}\text { 16- A } \\
\text { Cooperativa } \\
\text { adota políticas } \\
\text { de inclusão de } \\
\text { grupos } \\
\text { minoritários } \\
\text { como: negros, } \\
\text { mulheres, } \\
\text { deficientes, etc. }\end{array}$ & Percentual & 8,7 & 8,7 & 34,8 & 17,4 & 30,4 & 3,522 & 1,2746 & $\begin{array}{r}\text { Indiferente } \\
36,19 \%\end{array}$ \\
\hline $\begin{array}{l}\text { 17- As } \\
\text { informações } \\
\text { novas } \\
\text { oferecidas em } \\
\text { treinamentos } \\
\text { sobre } \\
\text { sustentabilidade } \\
\text { organizacional } \\
\text { são aplicadas } \\
\text { nas minhas } \\
\text { atividades do } \\
\text { dia a dia. }\end{array}$ & Frequência & 4,3 & 4,3 & 26,1 & 39,1 & 26,1 & 3,783 & 1,0426 & $\begin{array}{r}\text { Indiferente } \\
27,56 \%\end{array}$ \\
\hline \begin{tabular}{l}
\multicolumn{1}{c}{18 - A } \\
Cooperativa \\
desenvolve \\
sólidos \\
programas: de \\
educação, de \\
treinamento, de \\
aconselhamento \\
, de prevenção e \\
controle ao \\
meio ambiente, \\
sociedade e \\
economia.
\end{tabular} & Percentual & 4,3 & 0 & 39,1 & 39,1 & 17,4 & 3,652 & 0,9346 & $\begin{array}{r}\text { Indiferente } \\
25,59 \%\end{array}$ \\
\hline $\begin{array}{l}\text { 19- A } \\
\text { Cooperativa }\end{array}$ & Frequência & 2 & 0 & 6 & 8 & 7 & & & \\
\hline
\end{tabular}




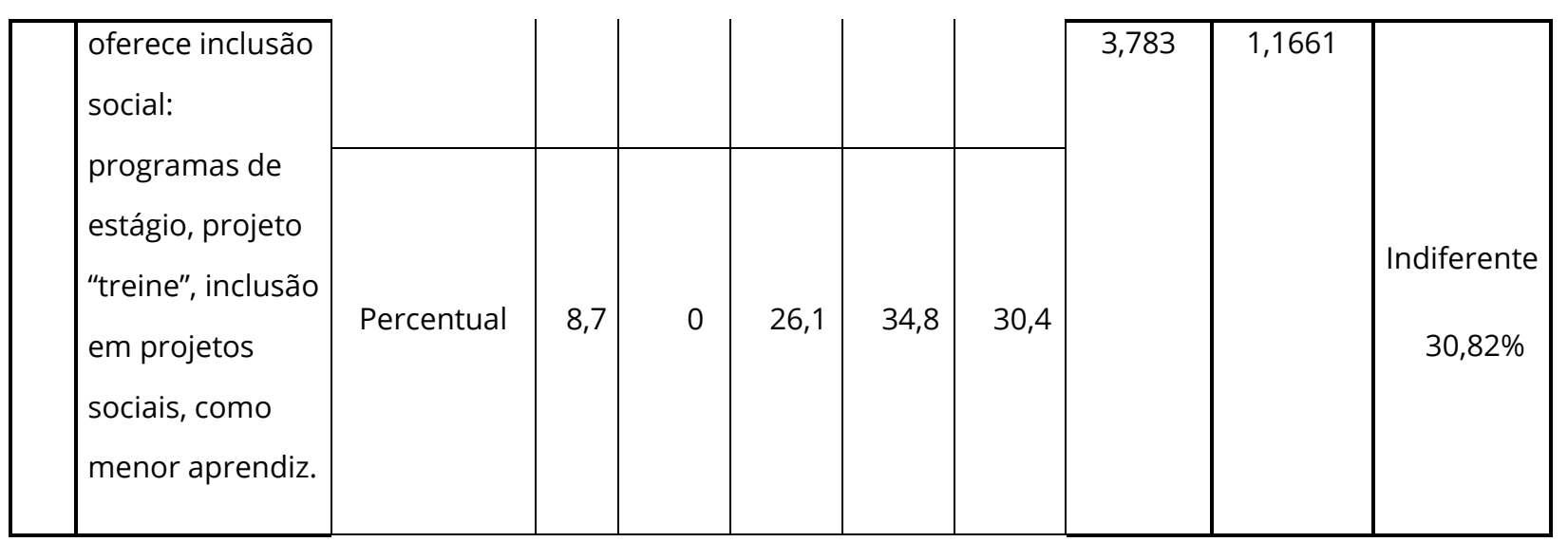

Fonte: A pesquisa e output SPSS.

É possível notar que os pesquisadores discordam parcial ou são indiferentes. A exceção é a questão "A Cooperativa realiza cursos de capacitação ou atualização para seus colaboradores e cooperados" que obteve concordância parcial. As respostas são homogêneas com exceção das questões 13 "A Cooperativa é comprometida com o desenvolvimento da sociedade, por meio de programas, como educação ambiental, coleta lixo reciclável, entre outros." E da questão 15- "A Cooperativa realiza cursos de capacitação ou atualização para de seus colaboradores e cooperados", onde os respondentes divergem as respostas destas questões.

Deste modo é possível observar que a cooperativa em estudo oferece capacitação para seus colaboradores e cooperados, com intuito de aumentar a produtividade dos colaboradores em seus cargos, buscando, principalmente, oferecer um produto de melhor qualidade aos seus cooperados. Deste modo, os cursos de capacitação de colaboradores e cooperados se tornam cada vez mais uma construção eficiente para o desenvolvimento da empresa como um todo.

Apresentados os comprovados da pesquisa, o próximo conteúdo trata das suas considerações finais, mencionando as conclusões, as contribuições do estudo para a Universidade, para as empresas, seus colaboradores e respectivos gestores, as limitações da pesquisa e oportunidades de novos estudos. No quadro 6 encontra-se o 
framework comparativo entre as respostas dos gestores e colaboradores.

Quadro 6: Comparação das respostas dos gestores e colaboradores

\begin{tabular}{|c|c|c|c|c|}
\hline INDICADORES & $\begin{array}{c}\text { GESTORES/ } \\
\text { COLABORADORES }\end{array}$ & POLÍTICAS & ESTRATÉGIAS & $\begin{array}{l}\text { PRÁTICAS/ } \\
\text { AÇÕES }\end{array}$ \\
\hline \multirow{2}{*}{ 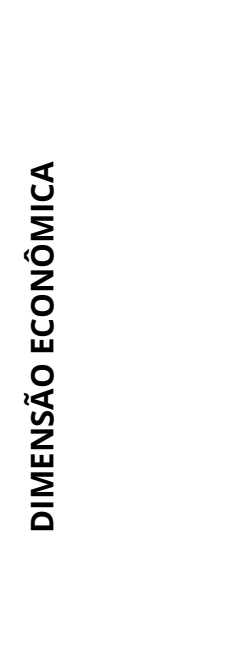 } & GESTORES & $\begin{array}{l}\text { Existem } \\
\text { políticas na } \\
\text { dimensão } \\
\text { econômica }\end{array}$ & $\begin{array}{l}\text { Possui estratégia e } \\
\text { diretrizes a serem } \\
\text { seguidas na dimensão } \\
\text { econômica, cada } \\
\text { cooperativa pode adaptar } \\
\text { a sua realidade. }\end{array}$ & $\begin{array}{l}\text { Existe práticas referente } \\
\text { a dimensão econômica } \\
\text { da sustentabilidade, } \\
\text { programas, Olhar para o } \\
\text { Futuro; programa } \\
\text { Juventude Cooperativista }\end{array}$ \\
\hline & COLABORADORES & $\begin{array}{l}\text { Existem } \\
\text { politicas na } \\
\text { dimensão } \\
\text { econômica }\end{array}$ & $\begin{array}{l}\text { É uma das dimensões } \\
\text { com maior frequência nas } \\
\text { respostas. }\end{array}$ & $\begin{array}{l}\text { Foi citados programas } \\
\text { como, olhar para o } \\
\text { Futuro; programa } \\
\text { Juventude Cooperativista }\end{array}$ \\
\hline \multirow{2}{*}{ 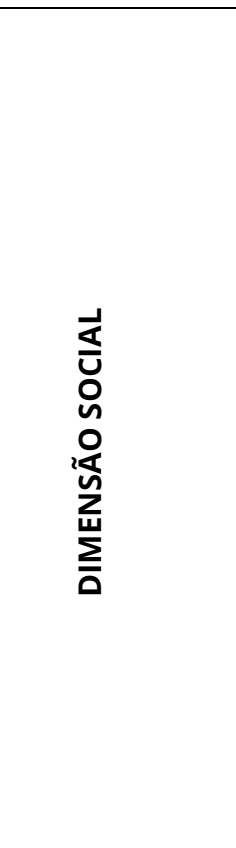 } & GESTORES & $\begin{array}{l}\text { Existem } \\
\text { politicas da } \\
\text { dimensão } \\
\text { social; }\end{array}$ & $\begin{array}{l}\text { Possui algumas } \\
\text { estratégias de gestão } \\
\text { voltada para a } \\
\text { sustentabilidade social, a } \\
\text { dimensão social } \\
\text { encontra-se em uma das } \\
\text { diretrizes da cooperativa. }\end{array}$ & $\begin{array}{l}\text { Contratação é dada } \\
\text { prioridade para as } \\
\text { pessoas da comunidade } \\
\text { local, trabalha com } \\
\text { programas trainner, do } \\
\text { treinamento para } \\
\text { colaboradores entre } \\
\text { outras práticas realizadas }\end{array}$ \\
\hline & COLABORADORES & $\begin{array}{l}\text { A cooperativa } \\
\text { trabalha com } \\
\text { programas na } \\
\text { dimensão } \\
\text { social }\end{array}$ & $\begin{array}{l}\text { Possui algumas } \\
\text { estratégias de gestão } \\
\text { voltada para a } \\
\text { sustentabilidade social }\end{array}$ & $\begin{array}{l}\text { Existem programas } \\
\text { desenvolvidos em escolas } \\
\text { e também com jovens }\end{array}$ \\
\hline
\end{tabular}




\begin{tabular}{|c|c|c|c|c|}
\hline \multirow{2}{*}{ 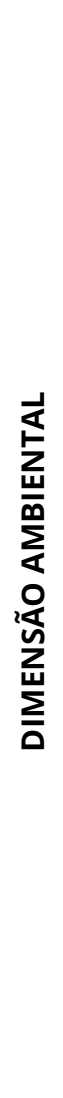 } & GESTORES & $\begin{array}{l}\text { Existem } \\
\text { politicas é } \\
\text { adaptado } \\
\text { para a } \\
\text { realidade de } \\
\text { cada região. }\end{array}$ & $\begin{array}{l}\text { As estratégias de } \\
\text { sustentabilidade } \\
\text { ambiental, não estão nas } \\
\text { diretrizes da cooperativa, } \\
\text { são executadas, mas por } \\
\text { outras singulares, não } \\
\text { tem nada sendo realizado } \\
\text { na cooperativa em estudo }\end{array}$ & $\begin{array}{l}\text { As práticas não se } \\
\text { encontram diretamente } \\
\text { relacionadas no cotidiano } \\
\text { da cooperativa, mas } \\
\text { acontecem de forma } \\
\text { indireta. }\end{array}$ \\
\hline & COLABORADORES & $\begin{array}{l}\text { Existem } \\
\text { algumas } \\
\text { políticas para } \\
\text { as questões } \\
\text { ambientais. }\end{array}$ & $\begin{array}{l}\text { Quando questionado se a } \\
\text { cooperativa realizada } \\
\text { programas internos que } \\
\text { objetive proteção ao meio } \\
\text { ambiente ou a } \\
\text { conscientização dos } \\
\text { colaboradores, a } \\
\text { frequência foi muito } \\
\text { baixa. }\end{array}$ & $\begin{array}{l}\text { Conforme observado nas } \\
\text { respostas dos } \\
\text { questionários pode-se } \\
\text { observar que a } \\
\text { frequência para as } \\
\text { respostas da dimensão } \\
\text { ambiental tem um nível } \\
\text { muito baixo. }\end{array}$ \\
\hline
\end{tabular}

Fonte: Elaborado a partir dos coletados entrevista e questionários.

Os resultados da análise do quadro 6 representam um comparativo entre as respostas dos gestores e colaboradores, abrangendo as políticas, estratégias e ações, considerando as dimensões e as condições de presença e ausência das mesmas. É possível notar que há semelhança entre as repostas dos gestores e colaboradores, o que permite afirmar que existe sincronia entre eles. A seguir apresentam-se as conclusões, contribuições, limitações e apontamentos para futuros estudos.

\section{CONSIDERAÇÕES FINAIS}

A pesquisa foi caracterizada como estudo de caso único, de caráter descritivo, de abordagem quantitativa e qualitativa, onde se pretendeu contribuir com o entendimento de ações estratégicas de uma cooperativa de crédito rural e as práticas de gestão nas dimensões econômicas, sociais e ambientais da sustentabilidade. 
Este estudo teve como objetivo principal analisar as relações entre as ações estratégicas de uma cooperativa de crédito rural e as práticas de gestão nas dimensões econômicas, sociais e ambientais da sustentabilidade organizacional. Nesse aspecto, o objetivo geral foi atendido, os quais efetivaram os testes estatísticos que analisaram as práticas que expressaram a maior concordância dos colaboradores para com as práticas de sustentabilidade nas dimensões econômica, social e ambiental, expressando quantitativamente a sua percepção sobre as práticas de gestão voltadas a sustentabilidade organizacional de sustentabilidade organizacional.

Foi possível identificar as práticas de sustentabilidade, por meio dos resultados da análise de conteúdo, pode-se inferir que as estratégias de sustentabilidade na cooperativa são criadas pela central Baser, e as cooperativas singulares podem adaptar conforme a sua realidade. É possível notar que a criação das estratégias acontece com maior intensidade no pilar econômico, onde existem diretrizes a serem seguidas, no pilar ambiental e social observam-se programas que são executados, porém a singular estudada Cresol vale das araucárias não executam atividades no pilar ambiental, devido às estratégias e práticas de sustentabilidade ambiental não estar diretamente vinculada, mas estarem atreladas de forma indireta na criação de estratégias e ações da cooperativa, como por exemplo, os programas "olhar para o futuro", "incentivo ao plantio de outras culturas, onde não se tenha que utilizar muito agrotóxico e gere mais renda para a família,", "Programa para os Jovens" e o "Programa Juventude Cooperativista".

Verificou-se o relacionamento entre as variáveis por meio do teste estatístico Correlação de Spearman, determinou-se as correlações das respectivas variáveis, verificando se cada uma delas está correlacionada de forma positiva, negativa ou nula. Com esse objetivo o teste estatístico demonstrou que duas das variáveis estão correlacionadas de forma positiva, sendo a dimensão social seguida da dimensão econômica. As práticas da dimensão ambiental devem ser planejadas e trabalhadas no cotidiano da cooperativa na forma de economizar água, energia elétrica, papel, 
combustível, evitar viagens desnecessárias para diminuir combustível, fora projetos específicos que podem ser desenvolvidos interna e externamente. Essas práticas não são percebidas nos serviços financeiros oferecidos aos cooperados, porque não trazem lucro para a instituição. Mas deveriam avaliar não só serviços financeiros, mas o dia a dia da organização. Entende-se que a cooperativa analisada não possui equilíbrio nos pilares econômico, social e ambiental como defende Elkington (2004, 2012) para que se tenha vantagem competitiva para com a sustentabilidade organizacional.

\subsection{Contribuições do Estudo}

Os resultados obtidos com esse estudo contribuem para a Estratégia como prática relacionada com as três dimensões da sustentabilidade organizacional, por meio da pesquisa realizada com os gestores e assistentes de negócios. Essa junção, que se apresenta positivamente correlacionada, pode ser melhor explorada pelos pesquisadores no campo das ciências sociais, intensificando estudos e fortificando os elementos das dimensões da sustentabilidade, assim como da estratégia como prática. Desse modo, o estudo em questão oportuniza uma agenda para que novas pesquisas sejam realizadas com os diversos stakeholders sobre a sustentabilidade organizacional e a estratégia como prática social.

Esta pesquisa contribui para os colaboradores, como forma de eles poderem avaliar as estratégias e práticas de gestão na sustentabilidade organizacional que consideram mais importantes e as menos relevantes, conforme transmitido para seus cooperados e colaboradores, dando assim, a oportunidade de os gestores poderem dar um enfoque maior no desenvolvimento das estratégias e práticas de gestão que, segundo estes, são mais relevantes ao seu desenvolvimento na Cooperativa.

Deste modo, este estudo é relevante no sentido de auxiliar na reflexão das estratégias e práticas de gestão na sustentabilidade organizacional, buscando 
alavancar as variáveis que mais têm significância para a cooperativa, seus cooperados e colaboradores. Podendo, assim, ser exemplo para outras organizações, a fim de espelhar-se na adoção de boas práticas de gestão na sustentabilidade organizacional e adotarem estratégias e práticas similares.

Poderá contribuir para a gestão da Cooperativa, fornecendo informações referentes às relações existentes entre as estratégias e práticas de gestão dos gestores e colaboradores nas dimensões da sustentabilidade. Mais precisamente para a Cooperativa estudada, contribuiu para identificar as estratégias e práticas de gestão de sustentabilidade que estão sendo executadas, bem como a relação entre as estratégias e as práticas de gestão.

Notas 1. Agradecemos às recomendações dos avaliadores da Revista de Gestão e Organizações Cooperativas, que contribuíram para a expansão e desenvolvimento do presente artigo.

\section{REFERÊNCIAS}

ALIANÇA COOPERATIVA INTERNACIONAL - ACl. Disponível em: https://www.ica.coop/es/cooperativas/identidad-alianza-cooperativa-internacional. Acesso em 10 MAIO. 2020.

ALYRIO, R. D. Métodos e técnicas de pesquisa em administração. Rio de Janeiro: Fundação CECIERJ, 2009. ISBN: 978-85-7648-465-3.

BARDIN, L. Análise de conteúdo. São Paulo: Edições 70, 2011.

BERGER, P. L.; LUCKMANN, T. A construção social da realidade. 24 ed. Petrópolis, RJ: Vozes, 2004.

BRASIL. Constituição. Constituição da República Federativa do Brasil. Brasília, DF: Senado Federal: Centro Gráfico, 1988. 292 p. Disponível em: http://www.senado.gov.br/atividade/const/con1988/con1988_04.02.2010/art_146_.asp. Acesso em: 20 de Set. 2018. 
BRUNACCI, A., E PHILIPPI, A. Jr.. A dimensão humana do desenvolvimento sustentável. In A. Jr. Philippi, E M. C. F. Pelicioni, (Orgs.). Educação ambiental e sustentabilidade (pp. 307-333). Barueri, São Paulo: Manole, 2014.CRESOL - Cooperativa de Crédito Rural com Interação Solidária. Disponível em: https://www.cresol.com.br/site/. Acesso em 20 Out. 2018.

CRESWELL, J. W.; PLANO CLARK, V. L. Pesquisa de métodos mistos. 2.ed. Porto Alegre: Penso, 2013.

CRUZ, Paulo Sergio Alves da. A filosofia cooperativista e o cooperativismo no Brasil e no mundo. Rio de Janeiro: COP Editora, 2001.

DIAS, M. DE O.; SILVA, C. A.; LUND, M. Brazilian Credit Cooperatives: Cresol Confederation Case. IOSR Journal of Business and Management (IOSR-JBM), 2019, vol. 21, n. 5, p. 11-19.

DYLLICK, T.; HOCKERTS, K. Beyond the business case for corporate sustainability. In: Business

Strategy and the Environment, v.11, p.130-141, 2002. Disponível em: https://instruct.uwo.ca/business/bus020-mwf/acs410/reading14.pdf. Acesso em: 20 JUN. 2019.

ELKINGTON, J. Enter the Triple Bottom Line. In: A. Henriques \& J. Richardson (Eds.). The Triple Bottom Line: Does it All Add Up? Assessing the Sustainability of Business and CSR (pp. 1-16). London: Earthscan Publications, 2004.

ELKINGTON, J. Canibais com garfo e faca. São Paulo: Makron Books, 2012.

FRANK, Walmor. Direito da sociedades Cooperativas: direito cooperativo. Saraiva, 1973.

GHIGLIONE, R. e B. Matalon (1995). O Inquérito- Teoria e Prática Oeiras, Celta Editora, 370 p.

GIDDENS, A. A constituição da sociedade. 2. Ed. São Paulo: Martins Fontes, 2003.

IRION, João Eduardo. Cooperativismo e economia social. São Paulo: STS, 1997. 343 p.

JARZABKOWSKI, P. Strategy as Practice: An activity-based approach. London: SAGE Publications, 2005.

JARZABKOWSKI, Paula; Balogun, Julia; Seidl, David. "Strategizing: The challenges of a practice perspective" Human Relations. v.60, n.1, 5-27, 2007.

KULAK, C. M.; STEFANO, S. R.; KUHL, M. R. Institucionalização de práticas de sustentabilidade. REUNA (ON LINE), v. 24, p. 67-88, 2019. 
LIMA, L. F. Estratégias e práticas de gestão, orientadas à sustentabilidade, apropriadas pelas cooperativas agropecuárias do sul do brasil. 2013. 154 f. Tese (Pós-Graduação em Administração, área de Concentração Estratégias e Organizações) - Setor de Ciências Sociais Aplicadas da Universidade Federal do Paraná, Curitiba.

LLEWELLYN, S.; NORTHCOTT, D. The "singular view" in management case studies qualitative research in organizations and management. An International Journal, v. 2, n. 3, p. 194-207, 2007.

MEINEM, Ênio; PORT, Márcio. O cooperativismo de crédito ontem, hoje e amanhã. Brasília: CONFEBRÁS, 2012. 429 p.

MINAYO, M. C. de S.; DESLANDES, F. S.; GOMES, R. Entrevista como técnica privilegiada de comunicação. p. 64-77 In: MINAYO, M. C. de S.; DESLANDES, F. S.; GOMES, R. Pesquisa Social: teoria, método e criatividade. 25. ed. Petrópolis: Vozes, 2007.

MUNCK, L. Gestão da sustentabilidade nas organizações: um novo agir frente à lógica das competências. São Paulo: Cengage Learning, 2014.

OKAYAMA, E. Y.; Et al,. Análise da produção científica em estratégia como prática. REBRAE. Revista Brasileira de Estratégia, Curitiba, v. 7, n. 2, p. 191-204, maio/ago. 2014

Portal do Cooperativismo Financeiro (PCF). Disponível em: https://www.cooperativismodecredito.coop.br/cooperativismo/historia-do-cooperativismo/os7-principios-do-cooperativismo/ 2020. Acesso em: 10 MAIO. 2020.

PORTER, M.E.; LINDE, C.V.D. Green and competitive: ending the stalemate. Harvard Business Review, v. 73, n. 5, p. 20-134, 1995.

SACHS, Ignacy. Desenvolvimento includente, sustentável, sustentado. Rio de Janeiro: Garamond, 2008. 152 p.

SCHEIDT, G. B.; STEFANO, S. R.; KOS, S. R. Desempenho da Sustentabilidade em uma Cooperativa de Crédito: uma proposta de análise na visão dos gestores. REVISTA DE ADMINISTRACAO IMED, v. 9, p. 71-93, 2019.

SROUR, Robert Henry. Poder, cultura e ética nas organizações / Robert Henry Srour. - 3.ed. Rio de Janeiro: Elsevier, 2012.

WOLFFENBÜTTEL, R. F. Sustentabilidade e ação socioeconômica: a rede produtiva do plástico verde. 2015. Dissertação (Programa de Pós-Graduação em Sociologia, Mestrado em Sociologia) - Universidade Federal do Rio Grande do Sul - UFRGS, Porto Alegre, 2015. Disponível

em: 
https://www.lume.ufrgs.br/bitstream/handle/10183/116472/000965062.pdf?sequence=1. Acesso em: 20 JUN. 2019.

WHITTINGTON, R. CAILLUET, L. The crafts of strategy. Long Range Planning, v.41, n.3, pp.241247, 2008.

WHITTINGTON, R. Completing the practice turn in strategy research. Organization studies, v. 27, n. 5, p. 613-634, 2006.

WHITTINGTON, R. Big Strategy/Small Strategy. Strategic Organization, v.10, n.3, pp.263- 268, 2012. 
